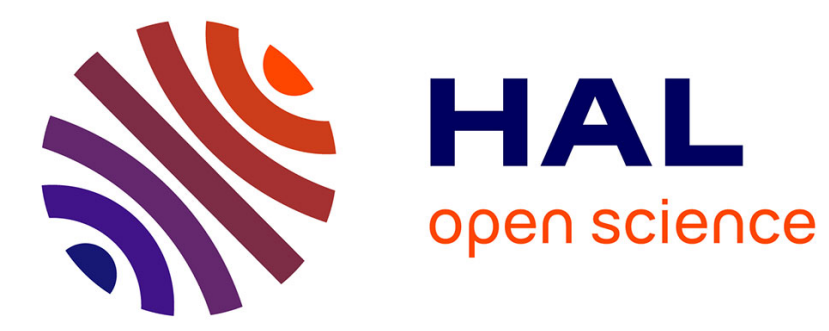

\title{
Applications of microsatellite-based Y chromosome haplotyping
}

Tatiana Zerjal, Manfred Kayser, Peter de Knijff, Patrick Dieltjes, Michael

Krawczak, Marion Nagy, Arpita Pandya, Chris Tyler-Smith, Lutz Roewer, Manfred Kayser', et al.

\section{To cite this version:}

Tatiana Zerjal, Manfred Kayser, Peter de Knijff, Patrick Dieltjes, Michael Krawczak, et al.. Applications of microsatellite-based Y chromosome haplotyping. Electrophoresis, 1997, 18 (9), pp.1602-1607. 10.1002/elps.1150180920 . hal-03378504

\section{HAL Id: hal-03378504 https://hal.science/hal-03378504}

Submitted on 14 Oct 2021

HAL is a multi-disciplinary open access archive for the deposit and dissemination of scientific research documents, whether they are published or not. The documents may come from teaching and research institutions in France or abroad, or from public or private research centers.
L'archive ouverte pluridisciplinaire HAL, est destinée au dépôt et à la diffusion de documents scientifiques de niveau recherche, publiés ou non, émanant des établissements d'enseignement et de recherche français ou étrangers, des laboratoires publics ou privés. 


\author{
Manfred Kayser' \\ Peter de Knijff ${ }^{2}$ \\ Patrick Dieltjes ${ }^{2}$ \\ Michael Krawczak ${ }^{3}$ \\ Marion Nagy ${ }^{\mathbf{1}}$ \\ Tatiana Zerjal ${ }^{4 *}$ \\ Arpita Pandya ${ }^{4}$ \\ Chris Tyler-Smith ${ }^{4}$ \\ Lutz Roewer
}

${ }^{1}$ Institut für Gerichtliche Medizin,

Humboldt-Universität zu Berlin,

Germany

${ }^{2}$ MGC-Department of Human

Genetics, Leiden University,

The Netherlands

${ }^{3}$ Institute of Medical Genetics, University of Wales, College of

Medicine, UK

${ }^{4}$ Department of Biochemistry,

University of Oxford, UK

\section{Applications of microsatellite-based $Y$ chromosome haplotyping}

\begin{abstract}
Y-chromosomal microsatellites have been investigated for the purposes of application to male identification, population genetics and population history. With nine markers, every male in a German population sample $(n=70)$ could be identified by an individual-specific $\mathrm{Y}$ microsatellite haplotype. The analysis of 474 unrelated males of nine human populations with seven markers revealed 301 different $\mathrm{Y}$ haplotypes. The analysis of molecular variance (AMOVA) approach was used to detect male population characteristics of $Y$ microsatellite haplotypes. With pairwise comparisons of inter-population variance, most of the populations could be distinguished significantly. Sixty individuals from different male populations in Asia and Northern Europe carrying a novel Y-chromosomal $\mathrm{T} \rightarrow \mathrm{C}$ transition show reduced microsatellite variability together with haplotype similarities. Microsatellite data suggest that the mutation occurred recently in Asia, supporting the hypothesis of Asian ancestry of some northern European populations.
\end{abstract}

\section{Introduction}

There are two uniparentally inherited parts of the human genome which allow the retracing of maternal and paternal lineages: mitochondrial (mt) DNA and the non-pseudoautosomal region on the $\mathrm{Y}$ chromosome. Both genetic materials are transferred without recombinational shuffling from generation to generation but can be modified by mutational events. While the study of mtDNA variability in reconstructing human genetic evolution is well established $[1,2]$, until recently the use of the $\mathrm{Y}$ chromosome has been hampered by the lack of appropriate polymorphic markers. Restriction fragment studies [3, 4] and sequence analyses [5-7] of the human $Y$ chromosome show a low level of nucleotide diversity compared to autosomes. Different theories have been proposed to explain these observations [8]. To date, only a small number of $Y$ chromosome point mutations have been reported $[6,7,9,10]$, but more are to be expected. Base substitutions are in general rare enough to be regarded as unique mutational events [8] and therefore identify monophyletic groups. Because of the low mutation rate, Y-chromosomal base substitutions are often restricted to particular population groups $[9,10]$. In contrast, the high level of variability of microsatellites resulting from the higher mutation rate makes them informative, in principle, in every comparative population analysis. However, the number of microsatellite loci on the $Y$ chromosome appears to be significantly reduced [11]. Only one tetrameric (DYS19) and three dimeric (YCAI-III) Y-chromosomal microsatellites were described in the first half of the decade $[12,13]$. Extensive worldwide population studies for DYS19 [14, 15] reveal differences in allele distributions for the major

Correspondence: Manfred Kayser, Institut für Gerichtliche Medizin, Humboldt-Universität zu Berlin, Hannoversche Strasse 6, D-10115 Berlin, Germany (Tel: +49-30-2093-7531; Fax: +49-30-2093-7240; E-mail: kayser@rz.charite.hu-berlin.de)

Keywords: Y chromosome / Microsatellites / Forensic application / Population genetics / Male evolution ethnic groups. It has recently been shown that two closely related populations (Dutch and German) can be significantly distinguished with four Y microsatellites by analysis of molecular variance (AMOVA) [16].

In this review we demonstrate Y-chromosomal microsatellite applications to male identification, population genetics and population history. We survey $10 \mathrm{Y}$ microsatellite loci and demonstrate their forensic discriminatory potential. Furthermore, we show the first results of a worldwide population study of Y-chromosomal microsatellites. We have also analyzed $Y$ microsatellite polymorphisms in combination with a novel base substitution on the $Y$ chromosome revealing Asian ancestry of some northern European populations.

\section{Materials and methods}

\subsection{Genetic screening}

DNA samples from 474 males of nine different population groups were studied - from Europe: 88 Dutch, 70 Germans, 30 Basques; from Asia: 36 Han-Chinese and 40 Khalkh-Mongolians; from Africa: 31 Central African Pygmies; from America: 54 Surinamese and 62 Greenland-Inuits and from Oceania: 63 Austronesians from the Trobriand Islands, Papua New Guinea. All males were analyzed at the tetranucleotide microsatellite loci DYS19, DYS389I, DYS389II, DYS390, DYS391 and DYS393 and at the trinucleotide locus DYS392. In addition, German males were analyzed at the tetranucleotide locus DYS385 and the dinucleotide loci YCAII and YCAIII [13]. PCR reactions were performed in a total volume of $25 \mu \mathrm{L}$ containing 20-100 ng genomic DNA, $50 \mathrm{~mm} \mathrm{KCl}, 10 \mathrm{~mm}$ Tris- $\mathrm{HCl}(\mathrm{pH} 8.3), 1.5 \mathrm{~mm} \mathrm{MgCl}_{2}$, $0.2 \mathrm{~mm}$ of each dNTP (Boehringer), and $20 \mathrm{pmol}$ of each primer (for sequence information see Table 1), with the

\footnotetext{
* Present address: International Center of Genetic Engineering and Biotechnology, Trieste, Italy
} 
forward primer 5'indodicarbocyanine (CY5) phosphoramidite or 5'FITC labeled and $1 \mathrm{U}$ Taq polymerase (Perkin Elmer or Promega) as single or multiplex PCR reactions (multiplexing: DYS19 with DYS389I,II and DYS390 with DYS391). For DYS19, DYS3891/II, DYS390, DYS391 and DYS392 (after preheating of $94^{\circ} \mathrm{C}$ for $3 \mathrm{~min}$ ) five cycles at $94^{\circ} \mathrm{C}$ for $15 \mathrm{~s}, 58^{\circ} \mathrm{C}$ for $20 \mathrm{~s}$, and $72^{\circ} \mathrm{C}$ for $20 \mathrm{~s}$ were used, continuing with 30 cycles of $94^{\circ} \mathrm{C}$ for $15 \mathrm{~s}, 54^{\circ} \mathrm{C}$ for $20 \mathrm{~s}$, and $72^{\circ} \mathrm{C}$ for $20 \mathrm{~s}$, finally $72^{\circ} \mathrm{C}$ for $10 \mathrm{~min}$. Thirty cycles of $94^{\circ} \mathrm{C}$ for $15 \mathrm{~s}, 58^{\circ} \mathrm{C}$ for $20 \mathrm{~s}$ and $72^{\circ} \mathrm{C}$ for $20 \mathrm{~s}$ were performed for DYS393, 30 cycles of $94^{\circ} \mathrm{C}$ for $60 \mathrm{~s}, 55^{\circ} \mathrm{C}$ for $60 \mathrm{~s}$ and $72^{\circ} \mathrm{C}$ for $90 \mathrm{~s}$ for DYS385, YCAIII and 30 cycles of $94^{\circ} \mathrm{C}$ for $60 \mathrm{~s}, 45^{\circ} \mathrm{C}$ for $60 \mathrm{~s}$ and $72^{\circ} \mathrm{C}$ for $90 \mathrm{~s}$ for YCAII. PCR products were resolved and detected on 6\% denaturing Hydrolink Long Ranger ${ }^{\text {TM }}$ gels (AT Biochem) using the ALF Express $^{\text {TM }}$ or ALF ${ }^{\text {TM }}$ DNA sequencer (Pharmacia). Lengths of the PCR fragments were determined by the Fragment Manager $^{\mathrm{M}}$ Version 1.2 software (Pharmacia). According to the guidelines of the International Society of Forensic Haemogenetics [17] the number of variable repeats has been used to designate the number of various alleles. Consistent allele designation was ensured by simultaneous running of allelic ladders for all loci in two independent laboratories (Berlin and Leiden). Sixty males carrying the mutated $\mathrm{C}$-allele chromosome of a novel $\mathrm{T} \rightarrow \mathrm{C}$ transition were investigated for the microsatellite loci DYS19, DYS3891/II, DYS390, DYS391, DYS392, and DYS393 - from Asia: 18 Yakut, 22 Buryat, 1 Khalkh, 1 Mjangad, 1 Khalimag, 1 Japanese and from Europe: 11 Finns, 2 Norwegians and 3 Russians. Furthermore, seven males belonging to the 'group 12' $\mathrm{Y}$ chromosome [Pandya et al., in preparation] were typed for the same loci: 2 Khalkhs (Mongolia), 4 Han-Chinese and 1 Indian.

\subsection{Statistical analysis}

Significance of differences in allele frequencies were tested using the $\mathrm{R}^{*} \mathrm{C}$ Fisher-Exact method by StatXact software package (Cytel Software Corporation, Cambridge MA, USA). Haplotype diversity has been calculated as described by Melton et al. [18]. Inter-population variance $\left(\Phi_{\mathrm{ST}}\right)$ of AMOVA were calculated in a pairwise method and the significance of differences in $\Phi_{\text {ST }}$ values were tested as described previously [16, 19].

\section{Results and discussion}

\subsection{Male identification}

Ten Y-chromosomal microsatellites were investigated for application to male identification. All Y microsatellites analyzed have been found to be highly or moderately polymorphic (Table 1). Alleles of most of the loci have been sequenced [De Knijff et al., in preparation] and the sequence of variable repeated motifs and other locus characteristics are given. The sequence analysis of DYS389 demonstrates that the priming site of the DYS389 forward primer has been duplicated, producing two clearly separable PCR products for each male. The larger product (DYS389II) includes the smaller product (DYS389I) [20].

Because all microsatellites are fully linked on the Y chromosome, single-locus information has been combined to construct extremely informative $\mathrm{Y}$ microsatellite haplotypes. The loci DYS19, DYS389I/II, DYS390, DYS391, DYS392 and DYS393 were chosen to define 7-locus

Table 1. $\mathrm{Y}$ chromosome microsatellite locus information

\begin{tabular}{|c|c|c|c|c|c|c|}
\hline Locus & $\begin{array}{l}\text { Sequence } \\
\text { of variable } \\
\text { repeats }\end{array}$ & $\begin{array}{l}\text { Number } \\
\text { of variable } \\
\text { repeats }\end{array}$ & $\begin{array}{l}\text { Number } \\
\text { of alleles }\end{array}$ & $\begin{array}{l}\text { Size range } \\
\text { of alleles (bp) }\end{array}$ & PCR primer sequence $\left(5^{\prime}-3^{\prime}\right)$ & Locus GDB-ID \\
\hline DYS19 & $(\mathrm{CTAT})_{\mathrm{n}}$ & $12-18$ & 7 & $182-206$ & $\begin{array}{l}\text { CTACTGAGTTTCTGTTATAGT } \\
\text { ATGGCATGTAGTGAGGACA }\end{array}$ & G00-121-409 \\
\hline DYS389I & $\begin{array}{l}(\text { CTAT })_{\mathrm{n}} / \\
(\mathrm{CTGT})_{\mathrm{n}}\end{array}$ & $8-13$ & 6 & $243-263$ & $\begin{array}{l}\text { CCAACTCTCATCTGTATTATCTAT } \\
\text { TCTTATCTCCACCCACCAGA }\end{array}$ & G00-366-108 \\
\hline DYS38911 ${ }^{\mathrm{b})}$ & $\begin{array}{l}(\mathrm{CTAT})_{\mathrm{n}}^{\prime} \\
(\mathrm{CTGT})_{\mathrm{n}}\end{array}$ & $23-30^{\mathrm{b})}$ & 8 & $353-381^{\mathrm{b})}$ & see DYS389I & see DYS389I \\
\hline DYS390 & $(\mathrm{CTAT})_{\mathrm{n}}$ & $20-27$ & 8 & $199-227$ & $\begin{array}{l}\text { TATATTTTACACATTTTTGGGCC } \\
\text { TGACAGTAAAATGAACACATTGC }\end{array}$ & G00-366-115 \\
\hline DYS391 & $(\text { CTAT })_{n}$ & $8-12$ & 5 & $275-291$ & $\begin{array}{l}\text { CTATTCATTCAATCATACACCCA } \\
\text { GATTCTTTGTGGTGGGTCTG }\end{array}$ & G00-366-118 \\
\hline DYS392 & $(\mathrm{ATT})_{\mathrm{n}}$ & $7-16$ & 8 & $236-263$ & $\begin{array}{l}\text { TCATTAATCTAGCTTTTAAAAACAA } \\
\text { AGACCCAGTTGATGCAATGT }\end{array}$ & G00-456-509 \\
\hline DYS393 & $(\text { GATA })_{n}$ & $12-15$ & 4 & $120-132$ & $\begin{array}{l}\text { GTGGTCTTCTACTTGTGTCAATAC } \\
\text { AACTCAAGTCCAAAAAATGAGG }\end{array}$ & G00-456-649 \\
\hline $\mathrm{DYS} 385^{\mathrm{c})}$ & $(\text { GAAA })_{n}{ }^{d)}$ & $9-22^{d)}$ & $28^{e)}$ & $360-412^{d)}$ & $\begin{array}{l}\text { AGCATGGGTGACAGAGCTA } \\
\text { TGGGATGCTAGGTAAAGCTG }\end{array}$ & G00-316-257 \\
\hline $\mathrm{YCA} \mathrm{II} \mathbf{I}^{\mathrm{c})}$ & $(\mathrm{CA})_{\mathrm{a}}$ & $-n$ & $15^{e)}$ & $149-161$ & $\begin{array}{l}\text { TATATTAAATAGAAGTAGTGA } \\
\text { TATCGATGTAATGTTATATTA }\end{array}$ & -g) \\
\hline YCA III') & $(\mathrm{CA})_{\mathrm{n}}$ & $19-25$ & $15^{e)}$ & $192-204$ & $\begin{array}{l}\text { CAACATTGTGTGAATGTGTGA } \\
\text { TCCTCAGAGAAGGAGAAACTA }\end{array}$ & -g) \\
\hline
\end{tabular}

a) Observed in the nine population groups $(n=474)$; number of classes of alleles for YCAIII found in a German population sample ( $n=70)$ and for DYS385, YCAII in the German and in an Austronesian population sample $(n=63)$.

b) DYS389II includes DYS389I [20].

c) Primers amplify two Y-chromosome specific PCR products.

d) Sequencing data for DYS385 are kindly provided by S. Meuser and P. M. Schneider, Mainz (manuscript in preparation).

e) Classes of alleles.

f) Alleles not yet fully sequenced.

g) Sequences are not submitted to the Human Genome Data Base (GDB) [13]. 
haplotypes. These microsatellites are moderately polymorphic, include only one Y-chromosomal locus and a number of them can be analyzed in a multiplex PCR. In a German population sample 63 different 7-locus haplotypes (discriminatory capacity of $90 \%$ ) were found in 70 unrelated males (Table 2). In order to explore the discriminatory capacity of $\mathrm{Y}$ microsatellites further we have increased the number of loci to include the highly polymorphic systems DYS385, YCAII and YCAIII. Each of these microsatellite systems consists of two variable Y-specific loci which are co-amplified during the PCR. Alleles cannot be unambiguously assigned to either of the two loci; thus allele pairs have been designated as 'allele classes'. Microsatellite systems containing two independently amplified variably repeated structures are in general much more polymorphic than microsatellites which include one variable locus only (Table 1). With an 8-locus haplotype (7-locus haplotype plus DYS385), the male discriminatory capacity could be increased by $7.1 \%$ with 68 haplotypes detected (Table 2). By adding YCAII, 69 of 70 Germans can be distinguished by this 9-locus haplotype. However, another 9-locus haplotype (7-locus haplotype plus DYS385, plus YCAIII) revealed complete individualization in the German sample - all 70 males could be identified by an individual-specific $Y$ microsatellite haplotype. This demonstrates the enormous potential of $\mathrm{Y}$ microsatellites for forensic and genealogical investigations, which includes identification of males and patrilineages, e.g. in paternity testing (especially in deficiency cases with male offsprings) and stain analysis [21-23, this issue]. Y microsatellites can be used confidently for exclusions, but the nonrecombinational inheritance of the $Y$ chromosome means that the probability calculation of a non-exclusion based on $Y$ polymorphisms alone will be problematic. $Y$ haplotypes are confined within paternal lineages; population substructuring is thus a major problem and an unknown number of male relatives of a suspect (or an alleged father) will share his $\mathrm{Y}$ chromosome [24].

\subsection{Population genetics}

To demonstrate the utility of chromosome $Y$ microsatellites for population genetics, the first results of a popula- tion survey at seven loci (DYS19, DYS3891/II, DYS390, DYS391, DYS392, and DYS393) are presented here (Kayser et al., in preparation). Nine worldwide population samples were chosen, including both more closely as well as more distantly related groups from Europe (Dutch, Germans and Basques), America (Inuits and Surinamese), Africa (Pygmies), Asia (Mongolians and Chinese) and from Oceania (Austronesians). Allele frequencies differed significantly between most of the nine population samples for most of the loci (data not shown). Not all alleles given in Table 1 were found in all groups and more alleles have been observed for all loci by screening other population samples [21]. In 474 individuals, 301 haplotypes were observed (Table 3). Haplotype diversity ranged between 0.90 and 0.99 . High numbers of unique and population-specific haplotypes were detected. Haplotype sharing was higher between the European populations than in the comparisons of more distantly distributed populations where only one or no haplotype was shared.

A pairwise AMOVA approach based on 7-locus haplotypes was used to investigate male population characteristics. AMOVA is the only method to calculate the genetic distance measure $\Phi_{\mathrm{ST}}$ based on haplotype differentiation patterns [19]. For all population samples analyzed, the intra-population variance was higher than the inter-population variance (data not shown). All of the pairwise population comparisons of inter-population variance show significant differences except for the Germans-Mongolians. In other words, for nearly all of the groups, compound $\mathrm{Y}$ microsatellite haplotypes reveal male population specificities which can be significantly distinguished by AMOVA (Kayser et al., in preparation). The observed significant difference of $\Phi_{\mathrm{ST}}$ for the DutchGermans confirms our previous findings by 4-locus haplotypes only [16].

The usefulness of microsatellite data for population genetics, for human evolutionary research and also for forensic application essentially depends on their mutation rate. A multicenter study evaluating Y-chromosomal microsatellites revealed a mutation rate for the tetranucleotide locus DYS19 of $3.2 \times 10^{-3}$ by studying 626

Table 2. Discriminatory capacity of microsatellite-based $\mathrm{Y}$ chromosome haplotypes in a German population sample $(n=70)$

\begin{tabular}{lcc}
\hline Loci analyzed & Number of haplotypes & Discriminatory capacity \\
\hline DYS19+DYS389I/II+DYS390+DYS391+DYS392+DYS393 & 63 & $90.0 \%$ \\
DYS19+DYS389I/II+DYS390+DYS391+DYS392+DYS393+DYS385 & 68 & $97.1 \%$ \\
DYS19+DYS3891/II+DYS390+DYS391+DYS392+DYS393+DYS385+YCAII & 69 & $98.6 \%$ \\
DYS19+DYS389I/II+DYS390+DYS391+DYS392+DYS393+DYS385+YCAIII & 70 & $100.0 \%$ \\
\hline
\end{tabular}

Table 3. Y chromosome haplotype information based on 7 microsatellite loci in 9 human population samples ${ }^{\text {a) }}$

\begin{tabular}{|c|c|c|c|c|c|c|c|c|c|c|}
\hline & Dut & Ger & Bas & Aus & Chi & Mon & Inu & Sur & Pyg & Comb \\
\hline Number of individuals & 88 & 70 & 30 & 63 & 36 & 40 & 62 & 54 & 31 & 474 \\
\hline Number of haplotypes & 65 & 63 & 17 & 40 & 34 & 29 & 22 & 47 & 18 & 301 \\
\hline Discriminatory capacity in $\%$ & 73.9 & 90.0 & 56.7 & 63.5 & 94.4 & 72.5 & 35.5 & 87.0 & 58.1 & - \\
\hline Haplotype diversity ${ }^{\text {b) }}$ & 0.98 & 0.99 & 0.94 & 0.98 & 0.99 & 0.97 & 0.90 & 0.99 & 0.95 & - \\
\hline
\end{tabular}

a) Dut, Dutch; Ger, Germans; Bas, Basques; Aus, Austronesians (Trobriand Islands); Chi, Chinese (Han); Mon, Mongolians (Khalkh); Inu, Inuits (Greenland); Sur, Surinamese; Pyg, Pygmies

b) Haplotype diversity has been calculated as described by Melton et al. [18]. 
father-son pairs [21]. Using deep-rooting paternal pedigrees, an average rate of $2.0 \times 10^{-3}$ per locus per generation has been estimated for seven tetranucleotide $Y$ microsatellites including six of the loci analyzed in this study [25]. Both Y-chromosomal mutation rates are of the same magnitude compared with the often used Weber and Wong [26] estimate of $2.1 \times 10^{-3}$ for 12 autosomal tetranucleotide repeats. From this, the very low number of shared haplotypes between population samples studied here (except the European groups) could be explained by recurrent mutation processes rather than by descent. Also, the observation of significantly different inter-population variance values could be a consequence of an early divergence of the respective populations, so that a possible genetic relationship is not detectable by the rapidly evolving $Y$ microsatellites. Due to their relatively high mutation rate, $Y$ microsatellites are, in our opinion, not very useful for population analyses of distantly related groups; on the other hand, for the purpose of comparing more closely related populations which have diverged during the past $30000-40000$ years, and for historical and forensic investigations, they are of considerable interest [27].

\subsection{Population history}

From the above, Y microsatellites alone offer little help in retracing distant events in human male evolution. But a combination of slowly evolving $Y$ point mutations and more rapidly evolving $Y$ microsatellites would be the method of choice for human evolutionary research. Recently, this approach has been used to answer the question whether a common ancestry of Asians and northern European population groups is likely [28]. The results of this study can be summarized as follows. A novel Y-chromosomal $\mathrm{T} \rightarrow \mathrm{C}$ transition was found in individuals of different Asian and northern European populations. Over one thousand males from various worldwide populations have been analyzed. Africans, Southern Europeans, Southern Asians, Oceanians and Americans carried the $\mathrm{T}$ allele which has also been found in chimpanzees and orangutans, suggesting that $T$ is ancestral. C-allele chromosomes were only observed in Asia (Buryats and Khalkhs from Mongolia, Yakut from Sibiria, Russians, Japanese) as well as in Northern Europe (Saami, Finns, Norwegians) and reach their highest frequency in Yakut, Buryats and Finns. The $\mathrm{T} \rightarrow \mathrm{C}$ transition has occurred on a Y-haplotypic background designated 'group 12' which has been detected in Southern and Eastern Asia (Pandya et al., in preparation).

Sixty males from nine population groups carrying the $\mathrm{C}$ allele were analyzed at seven $Y$ microsatellite loci in order to obtain a better understanding of the history of this mutation. Twenty-one compound 7-locus haplotypes were observed (Table 4). Where samples of $>10$ are available, each population contains multiple haplotypes: six haplotypes are found among 22 Buryats, six haplotypes are found among 18 Yakut and five haplotypes are found among 11 Finns. Thus the microsatellite haplotype diversity of $\mathrm{C}$-allele chromosomes within each population is similar. C-allele chromosomes show a reduced variability of $\mathrm{Y}$ microsatellite haplotypes compared with our data from the $\mathrm{Y}$ microsatellite population survey: 34 different haplotypes were observed in 36 Han-Chinese, 63 haplotypes in 70 Germans, 40 haplotypes in 63 Austronesians and 27 haplotypes in 38 Khalkh - all carrying the $T$ allele (see Table 3 ). In seven males from Mongolia, China, and India which belong to 'group 12' Y chromosomes we found six different microsatellite haplotypes (data not shown). Furthermore, we have used microsatellite haplotype analysis in order to deduce the ancestral microsatellite haplotype of the

Table 4. Microsatellite-based Y chromosome haplotype similarities of C-allele chromosomes ${ }^{a)}$

\begin{tabular}{|c|c|c|c|c|c|c|c|c|}
\hline Population & Haplotype & 19 & $389 \mathrm{I}$ & 389 II & 390 & 391 & 392 & 393 \\
\hline & 6 & 14 & 11 & $16^{+}$ & 23 & 11 & 14 & 14 \\
\hline Klaalimag & 1 & & & & & & & \\
\hline Buryat & 1 & & & & & & & \\
\hline Buryat & 1 & & & & & & & \\
\hline Buryat & 1 & & & & & & & \\
\hline Buryat & 1 & & & & & & & \\
\hline Buryat & 1 & & & & & & & \\
\hline Buryat & 1 & & & & & & & \\
\hline Buryat & 1 & & & & & & & \\
\hline Buryat & 1 & & & & & & & \\
\hline Buryat & 1 & & & & & & & \\
\hline Buryat & 1 & & & & & & & \\
\hline Buryat & 1 & & & & & & & \\
\hline Buryat & 1 & & & & & & & \\
\hline Buryat & 1 & & & & & & & \\
\hline Buryat & $2^{*}$ & & & & & & & \\
\hline Buryat & $2^{*}$ & & & & & & & \\
\hline Buryat & 3 & & & & & & & \\
\hline Buryat & 4 & & & & & & & \\
\hline Buryat & 5 & & & & & & & \\
\hline Buryat & 8 & & & & & & & \\
\hline Buryat & 8 & & & & & & & \\
\hline Buryat & 8 & & & & & & & \\
\hline Buryat & 8 & & & & & & & \\
\hline Mjangad & 6 & & & & & & & \\
\hline Khalkh & 6 & & & & & & & \\
\hline Russian & 6 & & & & & & & \\
\hline Russian & 9 & & & & & & & \\
\hline Russian & 10 & & & & & & & \\
\hline Yakut & 11 & & & & & & & \\
\hline Yakut & 11 & & & & & & & \\
\hline Yakut & 11 & & & & & & & \\
\hline Yakut & 13 & & & & & & & \\
\hline Yakut & 13 & & & & & & & \\
\hline Yakut & 13 & & & & & & & \\
\hline Yakut & 13 & & & & & & & \\
\hline Yakut & 15 & & & & & & & \\
\hline Yakut & 15 & & & & & & & \\
\hline Yakut & 15 & & & & & & & \\
\hline Yakut & 15 & & & & & & & \\
\hline Yakut & 15 & & & & & & & \\
\hline Yakut & 15 & & & & & & & \\
\hline Yakut & 15 & & & & & & & \\
\hline Yakut & 15 & & & & & & & \\
\hline Yakut & 12 & & & & & & & \\
\hline Yakut & 14 & & & & & & & \\
\hline Yakut & 16 & & & $\#$ & & & & \\
\hline Japanese & 7 & & & & & & & \\
\hline Finn & 17 & & & & & & & \\
\hline Finn & 17 & & & & & & & \\
\hline Finn & 17 & & & & & & & \\
\hline Finn & 17 & & & & & & & \\
\hline Finn & 17 & & & & & & & \\
\hline Finn & 17 & & & & & & & \\
\hline Finn & 17 & & & & & & & \\
\hline Finn & 18 & & & & & & & \\
\hline Finn & 19 & & & & & & & \\
\hline Finn & 20 & & & & & & & \\
\hline Finn & 21 & & & & & & & \\
\hline Norwegian & 17 & & & & & & & \\
\hline Norwegian & 6 & & & & & & & \\
\hline
\end{tabular}

a) $\square$, same allele; $\square$, variation in one or two (" three) units Haplotypes are designated according to [28] and standard microsatellite allele nomenclature has been used according to [21]. All 7-locus haplotypes in the table refer to haplotype 6 , which contains the most common microsatellite allele in $\mathrm{C}$ chromosomes at each locus. + DYS389II does not include variation at DYS389I. * Deduced from network analysis, haplotype 2 is most likely ancestral for all C-allele chromosomes [28]. 
chromosome on which the $\mathrm{T} \rightarrow \mathrm{C}$ transition occurred and thus the direction of $\mathrm{C}$-allele chromosome migration. Separate networks linking the C-allele or 'group 12' microsatellite haplotypes were constructed and then linked together. The link between the two networks identifies the most likely $\mathrm{C}$-allele ancestral haplotype. It occurs at the $\mathrm{C}$-allele haplotype 2, which is found only in Buryats from Mongolia (see Table 4). Since all of the 'group 12' Y chromosomes occur in Asia and the possible ancestral microsatellite haplotype is found in Asia, it is likely that the $\mathrm{T} \rightarrow \mathrm{C}$ transition occurred in Asia. The high frequency in northern European populations might be explained by migration of Uralic speakers and/or genetic drift in a small founder population containing both European and Asian elements [28].

The reduced microsatellite variability of the $\mathrm{C}$-allele chromosomes together with haplotype similarities suggest that the base substitution has arisen recently. In order to estimate the time that it has taken the C-allele chromosomes to spread through these populations, the mean number of microsatellite mutations was counted that had accumulated in the 60 chromosomes [29], assuming that each size change represents a different mutation and the number of back-mutations is negligible. Using haplotype 2 as ancestral, we find on average 3.1 mutations per haplotype, or 0.44 mutations per locus. With the average $\mathrm{Y}$ microsatellite mutation rate of $2.0 \times$ $10^{-3}$ per locus per generation [25], these mutations would accumulate in 220 generations: approximately 4400 years if the generation time is 20 years. If only the six tetranucleotide loci are included in the calculation, this approach would give a figure of 4100 years. These data are surprisingly recent and it is difficult to know how much confidence should be placed in them, especially since little is known about population history during this period and there may have been bottlenecks leading to loss of lineages. One major source of error in estimating the age of the $\mathrm{C}$ chromosome is the inability to distinguish between single and recurrent microsatellite mutations. Some of the events scoring as single mutations may in fact be multiple. This of course would lead to an underestimation of the age of the $\mathrm{C}$-allele chromosome. Another source of error is the generation time used for the calculation.

\section{Concluding remarks}

Y-chromosomal microsatellite haplotypes are useful for human male identification because of their high discriminatory capacity. $Y$ microsatellites are also appropriate tools in population genetics because compound haplotypes reveal male population specificities which can be significantly distinguished by AMOVA. Because of the relatively high mutation rate of Y microsatellites they are useful for the purpose of comparing closely related populations rather than populations which have diverged long ago. Alone they seem to offer little help in tracing back ancient events in human evolution. But a combined survey of $\mathrm{Y}$ point mutation markers together with $\mathrm{Y}$ microsatellites can reveal human population origin and migration history very efficiently. This combined approach will probably be the method of choice for fur- ther genetic research on human male evolution. Y microsatellites can be applied for forensic as well as for genealogical, historical and archaeological studies. For the latter investigations a sufficient stability of microsatellitebased $\mathrm{Y}$ chromosome haplotypes as a prerequisite for connecting male relatives from different generations can be assumed.

We are indebted to all the donors of blood samples for making this study possible. We thank Wulf Schiefenhövel, Luigi Bernini, Jorgen Jespersen, Mark Jobling, Raoul Heller, Bumbein Dashnyam, Shinji Harihara, Koji Shimizu, Dashnyam Semjidmaa, Antti Sajantila, Pia Salo, Michael $H$. Crawford and Oleg $V$. Evgrafov for collecting or providing samples and two reviewers for helpful comments. Carmen Krüger is gratefully acknowledged for preparing the German DNA samples. This research was supported by the Deutsche Forschungsgemeinschaft (Ro 1040/2-1, 1040/2-2 and $\mathrm{Kr}$ 1093/5-1), A.P. was funded by the BBSRC and C.T.-S. by the CRC. Participation of M.K. in the Fourth International DNA Fingerprinting Conference was made possible by grants from the Deutsche Forschungsgemeinschaft.

Received January 21, 1997

\section{References}

[1] Vigilant, L., Stoneking, M., Harpending, H., Hawks, K., Wilson, A. C., Science 1991, 253, 1503-1507.

[2] Stoneking, M., Evol. Anthropol. 1993, 2, 60-73.

[3] Jakubiczka, S., Arnemann, J., Cooke, H. J., Krawczak, M., Schmidtke, J., Hum. Genet. 1989, 84, 86-88.

[4] Malaspina, P., Persichetti, F., Noveletto, C., Iodice, C., Terrenato, L., Prantera, G., Ann. Hum. Genet. 1990, 54, 297-305.

[5] Dorit, R. L., Akashi, H., Gilbert, W., Science 1995, 268, 1183-1185.

[6] Hammer, M. F., Nature 1995, 378, 376-378.

[7] Whitfield, L. S., Sulston, J. E., Goodfellow, P. N., Nature 1995, 378, $379-380$.

[8] Jobling, M. A., Tyler-Smith, C., Trends. Genet. 1995, 11, 449-456.

[9] Seielstad, M. T., Hebert, J. M., Lin, A. A., Underhill, P. A., Ibrahim, M., Volirath, D., Cavalli-Sforza, L. L., Hum. Mol. Genet. 1994, 3, 2159-2161.

[10] Underhill, P. A., Jin, L., Zemans, R., Oefner, P. J., Cavalli-Sforza, L. L., Proc. Natl. Acad. Sci. USA 1996, 93, 196-200.

[11] Spurdle, A. B., Jenkins, T., Curr. Opin. Genet. Dev. 1992, 2, 487-491.

[12] Roewer, L., Arnemann, J., Spurr, N. K., Grzeschik, K.-H., Epplen, J. T., Hum. Genet. 1992, 89, 389-394

[13] Mathias, N., Bayès, M., Tyler-Smith, C., Hum. Mol. Genet. 1994, 3 , 115-123.

[14] Gomolka, M., Hundrieser, J., Nürnberg, P., Roewer, L., Epplen, J. T., Epplen, C., Hum. Genet. 1994, 93, 592-596.

[15] Santos, F. R., Gerelsaikhan, T., Munkhtuja, B., Oyunsuren, T., Epplen, J. T., Pena, S. D. J., Hum. Genet. 1996, 97, 309-313.

[16] Roewer, L., Kayser, M., Dieltjes, P., Nagy, M., Bakker, E., Krawczak, M., de Knijff, P., Hum. Mol. Genet. 1996, 5, 1029-1033.

[17] DNA Commission of the JSFH, Int. J. Legal Med. 1994, 107, $159-160$.

[18] Melton, T., Peterson, R., Redd, A. J., Saha, N., Sofro, A. S. M., Martinson, J., Stoneking, M., Am. J. Hum. Genet. 1995, 57, $403-414$.

[19] Excoffier, L., Smouse, P. E., Quattro, J. M., Genetics 1992, 131, 479-491.

[20] Cooper, G., Amos, W., Hoffman, D., Rubinsztein, D. C., Hum. Mol. Genet. 1996, 5(11), 1759-1766.

[21] Kayser, M., Caglià, A., Corach, D., Fretwell, N., Gehrig, C., Graziosi, G., Heidorn, F., Herrmann, S., Herzog, B., Hidding, M., Honda, K., Jobling, M., Krawczak, M., Leim, K., Meuser, S., Meyer, E., Oesterreich, W., Pandya, A., Parson, W., Penacino, G., 
Perez-Lezaun, A., Piccinini, A., Prinz, M., Schmitt, C., Schneider, P. M., Szibor, R., Teifel-Greding, J., Weichhold, G., de Knijff, P., Roewer, L., Int. J. Legal Med. 1997, 110, 125-133; 141-149.

[22] Kayser, M., de Knijff, P., Dieltjes, P., Krawczak, M., Nagy, M., Zerjal, T., Pandya, A., Tyler-Smith, C., Roewer, L., Electrophoresis 1997, 18, 1602-1607.

[23] Prinz, M., Boll, K., Baum, H., Shaler, B., For. Sci. Int. 1997, 85, 209-218.

[24] Jobling, M. A., Pandya, A., Tyler-Smith, C., Int. J. Legal Med. $1997,110,118-124$.

[25] Heyer, E., Puymirat, J., Dieltjes, P., Bakker, E., de Knijff, P., Hum. Mol. Genet. 1997, 6, 799-803.

[26] Weber, J. L., Wong, C., Hum. Mol. Genet. 1993, 2, 1123-1128.

[27] De Knijff, P., Kayser, M., Caglià, A., Corach, D., Fretwell, N., Gehrig, C., Graziosi, G., Heidorn, F., Herrmann, S., Herzog, B.,
Hidding, M., Honda, K., Jobling, M., Krawczak, M., Leim, K., Meuser, S., Meyer, E., Oesterreich, W., Pandya, A., Parson, W., Penacino, G., Perez-Lezaun, A., Piccini, A., Prinz, M., Schmitt, C., Schneider, P. M., Szibor, R., Teifel-Greding, J., Weichhold, G., Roewer, L., Int. J. Legal Med. 1997, 110, 134-140.

[28] Zerjal, T., Dashnyam, B., Pandya, A., Kayser, M., Roewer, L., Santos, F., Schiefenhövel, W., Fretwell, N., Jobling, M. A., Harihara, S., Shimizu, K., Semjidmaa, D., Sajantila, A., Salo, P., Crawford, M. H., Ginter, E. K., Evgrafov, O. V., Tyler-Smith, C., Am. J. Hum. Genet. 1997, 60, 1174-1183.

[29] Bertranpetit, J., Calafell, F., in: Chadwick, D., Cardew, G. (Eds.), Variation in the Human Genome, John Wiley, Chichester 1996, pp. 97-118. 